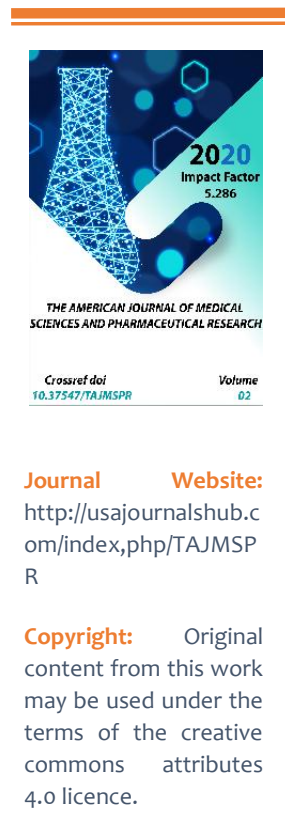

\title{
Comparative Analysis Of Endoscopic Methods Of Hemostasis In Bleeding From Esophageal Varicose Veins
}

\author{
Kadirov Rustam Nodirovich \\ Candidate of Medical Sciences, Republican scientific center of emergency medicine, Tashkent, \\ Uzbekistan
}

\section{ABSTRACT}

The Relapses gastroezofagale bleedings (GEK) beside sick with portal hypertension (PG) are one of the the most complex problems of modern medicine. As of Worldwide organization of the public health death-rate from cirrhosis liver and his (its) complications occupies for presentday day eighth place in structure general mortality. Esohpago-gastric bleedings, forming from 5 before $42 \%$ all gastrointestinal bleedings, are one of the main reasons to deaths sick with syndrome portal hypertension. The Real danger of the syndrome portal hypertension is connected with bleeding from varicose extended vein gullets and belly (VRVPZH), since death-rate from the first episode of the bleeding forms 50-70\%. The High percent of the complications survival and low sick dictate need of the improvement medical tacticians at bleedings from varicose extended vein gullets. At present for stop and preventive maintenances of the bleedings from varicose extended вен gullets (VRVP) use the facility an endockopic, medikamentoz, and surgical gemostaz. Our purpose to introduce in practical person endockopic scleroterapy and alloying at bleedings under varicose extended вен gullets. In consequence of which will is reached reduction of the relapse of the repeated bleeding and complications, miniinvaziveness method and mortality.

\section{KEYWORDS}

Cirrhosis liver, portal hypertension, bleeding, endoscopic sclerotherapy end alloying. 


\section{INTRODUCTION}

Bleeding from varicose veins ( $\mathrm{VV}$ ) of the esophagus and stomach is a dangerous complication of portal hypertension, which is accompanied by high mortality. Mortality in the first episode of bleeding in patients with cirrhosis of the liver exceeds $50 \%[1,2,3,4]$. in $30 \%$ of patients, repeated bleeding occurs within the first 6 weeks, in $70 \%$ of patients during the first year, if they did not have preventive medical measures $[5,6,7]$. The most frequent source of bleeding is esophageal VV, but bleeding from the stomach $\mathrm{VV}$ is more massive, often relapses, leading to fatal outcomes $[8,9,10]$. According to $\mathrm{WHO}$ and foreign authors, varicose veins in the stomach are detected in $5-33 \%$ of patients with portal hypertension [3, 11].The variety of different methods of stopping bleeding indicates dissatisfaction with their results, and still remain controversial and controversial issues of surgical tactics in acute bleeding, the feasibility and consistency of using various methods of hemostasis, the choice of a method for correcting $\mathrm{PH}[5,6,9]$. On the other hand, the poor tolerance of patients with cirrhosis of the liver ( $\mathrm{CoL}$ ) to any surgical interventions has led to an active search and development of a rational combination of effective minimally invasive interventions.

\section{THE PURPOSE OF THE STUDY}

To evaluate the effectiveness of treatment of active bleeding from the VVEaS using endoscopic hemostasis technologies.

\section{MATERIAL AND METHODS OF RESEARCH}

The analysis of complex clinical examination and treatment of 250 patients with $\mathrm{CoL}$ and
PH syndrome observed from 2014 to 2018 in the SBoRSCEC was carried out. In all cases, intrahepatic $\mathrm{PH}$ was diagnosed in the study groups. There were 165 males (66.0\%) and 85 females (34.0\%). The ratio of male and female patients in the study groups was 2.96 in the main group and 3.03 in the control group. The average age was $45.6 \pm 17.4$ years and $47.2 \pm 15.6$ years, respectively. By gender and age, the groups were comparable for analysis.Etiological factors of $\mathrm{CoL}$ development in patients of the main group were: viral hepatitis b 96, alcoholism in 23 cases, in the remaining 20 cases the factor was not determined. In all patients with intrahepatic $\mathrm{PH}$, the cause of their disease was cirrhosis of the liver. In the main group, 23 patients were assigned to the child-Pugh functional class $A, 17$ patients were assigned to the control group; 57 and 49 patients were assigned to class $\mathrm{B}$, and 59 and 40 patients were assigned to class C. In $42.5 \%$ and $37.7 \%$ of cases, patients were admitted in severe functional class $\mathrm{C}$, while decompensation was due to the phenomena of liver failure against the background of bleeding. The main group included 139 patients who underwent endoscopic ligation (EL). The control group included 106 patients who underwent standard ES with subsequent installation of the Blackmore-Sengstaken probe. All patients were admitted as an emergency due to bleeding from the VVES, while 65 (46.8\%) patients of the main group and 45 (42.4\%) of the control group at the time of admission had ongoing bleeding, while the rest had sustained bleeding. The distribution of patients by the degree of bleeding activity in the study groups is shown in table 1. 
The American Journal of Medical Sciences and Pharmaceutical Research (ISSN - 2689-1026)

Published: August 02, 2020 | Pages: 1-10

Doi:https://doi.org/10.37547/TAJMSPR/Volume02Issue08-01

Table 1

The distribution of the patients according to the degree of active bleeding on endoscopic features (Forrest,1974)

\begin{tabular}{|l|l|l|l|l|l|l|}
\hline \multirow{2}{*}{$\begin{array}{l}\text { Endoscopic sign of } \\
\text { bleeding }\end{array}$} & \multicolumn{2}{|l|}{$\begin{array}{l}\text { Main } \\
(n=139)\end{array}$} & \multicolumn{2}{l|}{$\begin{array}{l}\text { Control group } \\
(n=106)\end{array}$} & \multicolumn{2}{l|}{ All $(n=245)$} \\
\cline { 2 - 8 } & A6c. & $\%$ & A6c. & $\%$ & A6c. & $\%$ \\
\hline Forrest I a & 29 & $20,9 \%$ & 21 & $19,8 \%$ & 50 & $20,4 \%$ \\
\hline Forrest I b & 36 & $25,9 \%$ & 24 & $22,6 \%$ & 60 & $24,5 \%$ \\
\hline Forrest II a-b & 45 & $32,4 \%$ & 33 & $31,1 \%$ & 78 & $31,8 \%$ \\
\hline Forrest II c & 15 & $10,8 \%$ & 15 & $14,2 \%$ & 30 & $12,2 \%$ \\
\hline Forrest III & 14 & $10,1 \%$ & 13 & $12,3 \%$ & 27 & $11,0 \%$ \\
\hline TOTAL & 139 & $100,0 \%$ & 106 & $100,0 \%$ & 245 & $100,0 \%$ \\
\hline
\end{tabular}

As can be seen from the table, active bleeding (Forrest I a-b) at the time of endoscopy, which required $\mathrm{EL}$, was detected in $65(46.8 \%)$ patients of the main group and 45 (42.4\%) patients of the control group. The effectiveness of endoscopic hemostasis (table 2) when performing traditional sclerotherapy followed by the installation of a Blackmore probe averaged $68.9 \%$ and, depending on the intensity of bleeding, ranged from $61.9 \%$ for Forrest I-a to $75.0 \%$ for Forrest I-b. The use of $E L$ in the main group improved this indicator to an average of $83.1 \%$, while the most intense bleeding corresponding to Forrest $\mathrm{I}-\mathrm{a}$ was stopped in $75.9 \%$ of patients, and with Forrest I-b this indicator reached $88.9 \%$.

Table 2

Effectiveness of endoscopic hemostasis depending on the activity of bleeding

\begin{tabular}{|l|l|l|l|l|}
\hline $\begin{array}{l}\text { Endoscopic sign of } \\
\text { bleeding }\end{array}$ & $\begin{array}{l}\text { Main } \\
(n=65)\end{array}$ & group & $\begin{array}{l}\text { Control group } \\
(n=45)\end{array}$ & All $(n=110)$ \\
\hline
\end{tabular}


The American Journal of Medical Sciences and Pharmaceutical Research (ISSN - 2689-1026)

Published: August 02, 2020 | Pages: 1-10

Doi:https://doi.org/10.37547/TAJMSPR/Volume02Issue08-01

\begin{tabular}{|c|c|c|c|c|c|c|}
\hline & A6c. & $\%$ & A6c. & $\%$ & A6c. & $\%$ \\
\hline \multicolumn{7}{|c|}{ Effective endoscopic hemostasis } \\
\hline Forrest I a & 22 & $75,9 \%$ & 13 & $61,9 \%$ & 35 & $70,0 \%$ \\
\hline Forrest I b & 32 & $88,9 \%$ & 18 & $75,0 \%$ & 50 & $83,3 \%$ \\
\hline Total & 54 & $83,1 \%$ & 31 & $68,9 \%$ & 85 & $77,3 \%$ \\
\hline \multicolumn{7}{|c|}{ Ineffective endoscopic hemostasis } \\
\hline Forrest I a & 7 & $24,1 \%$ & 8 & $38,1 \%$ & 15 & $30,0 \%$ \\
\hline Forrest I b & 4 & $11,1 \%$ & 6 & $25,0 \%$ & 10 & $16,7 \%$ \\
\hline Total & $\mathbf{1 1}$ & $16,9 \%$ & 14 & $31,1 \%$ & 25 & $22,7 \%$ \\
\hline
\end{tabular}

The frequency of unsatisfactory ES results with active bleeding followed

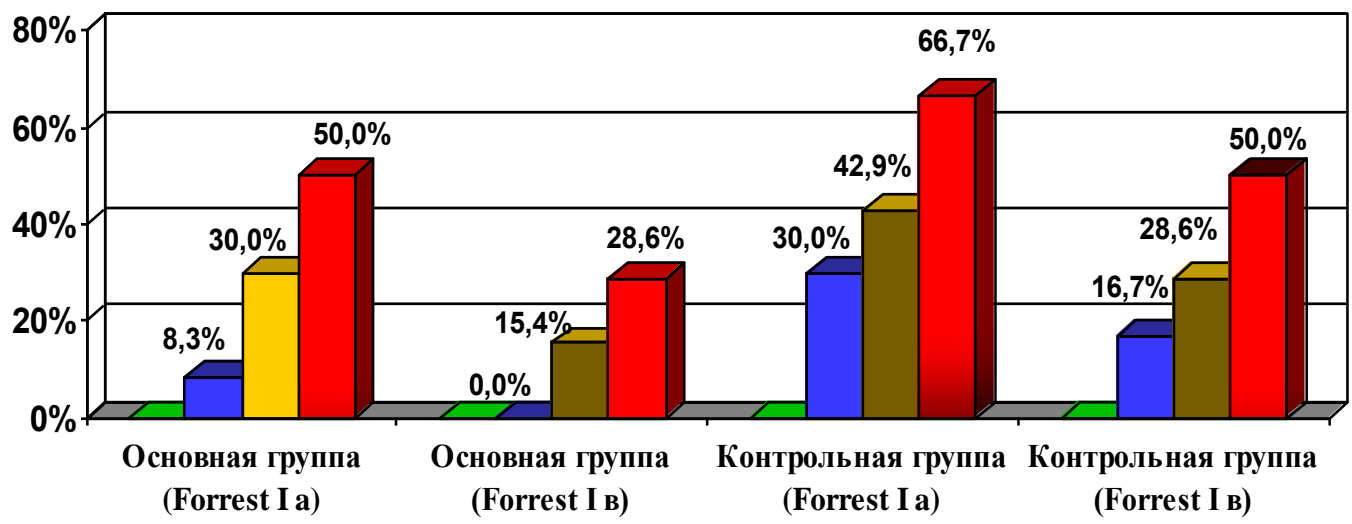

$\square$ c/3 $\square$ н/3 $\square$ КЭП $\quad \square$ Кардия желудка

by the use of a standard BlackmoreSengstaken probe, depending on the source level and intensity of bleeding, ranged from
$16.7 \%$ (n/3, Forrest I-b) to $66.7 \%$ (gastric cardia, Forrest $\mathrm{I}-\mathrm{a}$ ) and averaged $31.1 \%$, while $\mathrm{EL}$, allows reducing these indicators to $8.3-50 \%$ of 
cases, depending on the source level and intensity of bleeding, which averaged $16.9 \%$ (Fig.1).

Figure 1. Frequency of unsatisfactory results of endoscopic hemostasis in active bleeding, depending on the source level and intensity of bleeding. The mortality rate in the General group of patients was $26.5 \%$ (65 patients out of 245 died in the nearest period). In the main group, the mortality rate was $20.9 \%$, in the control group -34.0\%. Depending on the level of the source of bleeding, the highest level of this indicator was in patients with bleeding from the stomach cardia and was $30.8 \%$ and $44.4 \%$, respectively. At the same time, the mortality rate in the main group was on average 1.5-2 times lower than in the control group. Long-term results were observed in 83 (71.6\%) patients of the main group and 52 (69.3\%) patients of the control group. At various times after discharge, 32 (38.6\%) patients of the main group and 27 (51.9\%) of the control group were treated for relapsed bleeding from the VVES. A total of 135 patients with recurrent bleeding received 59 patients, which was $43.7 \%$. The analysis of the time factor showed that the highest frequency of relapse was noted in terms of up to 1 month after the ES. At the same time, if the frequency of this complication in the main group was $12.0 \%$ (10 patients), in the control group it reached $23.1 \%$ (12 patients), which is shown in table 3 .

Table 3

Frequency of relapses of VVES bleeding in the long-term period after endoscopic hemostasis

\begin{tabular}{|l|l|l|l|l|}
\hline \multirow{2}{*}{ Observation time } & \multicolumn{2}{|l|}{$\begin{array}{l}\text { Main group } \\
(n=83)\end{array}$} & \multicolumn{2}{l|}{$\begin{array}{l}\text { Control group } \\
(n=52)\end{array}$} \\
\cline { 2 - 5 } & A6c. & $\%$ & A6c. & $\%$ \\
\hline Up to 1 month & 10 & $12,0 \%$ & 12 & $23,1 \%$ \\
\hline Up to 3 months & 6 & $7,2 \%$ & 4 & $7,7 \%$ \\
\hline Up to 6 months & 5 & $6,0 \%$ & 3 & $5,8 \%$ \\
\hline Up to 1 year & 4 & $4,8 \%$ & 3 & $5,8 \%$ \\
\hline Up to 3 years & 7 & $8,4 \%$ & 5 & $9,6 \%$ \\
\hline Total & 32 & $38,6 \%$ & 27 & $51,9 \%$ \\
\hline
\end{tabular}

In terms after one month after endoscopic hemostasis, the frequency of relapse was approximately the same, some increase in this complication was detected in the follow-up period from 1 to 3 years. It should be noted that the recurrence of bleeding led to an increase in the mortality rate to $43.8 \%$ (14 patients) in the main group and $44.4 \%$ (12 patients) in the control group. Monitoring of CoL patients in dynamics showed that 23 (27.7\%) patients died from increasing liver failure in the main group, the mortality rate 
against the background of recurrent bleeding (for the General group of patients - 83) was $16.9 \%$ (14 cases), and the overall mortality rate reached $44.6 \%$ (37) cases. In the control group, this indicator was slightly higher, amounting to $18(34,6 \%), 12(23,1 \%)$ and $30(57.7 \%)$ patients, respectively.

Studies have shown that in patients with CoL who underwent endoscopic hemostasis for stopping and (or) preventing recurrence of bleeding from the VVES the long-term period of observation, the phenomena of progressive fatal liver failure by 3 years of observation reach $34.6 \%$, and the frequency of recurrence of hemorrhage is $23.1 \%$, increasing the overall mortality rate to $57.7 \%$ of cases, with the most critical periods being up to 1 month and from 1 year to 3 years. In turn, the use of EL allowed to reduce this indicator for recurrent bleeding to $16.9 \%$, while their higher efficiency allowed to reduce the risk of fatal liver failure in terms of up to 1 month of follow-up from $11.5 \%$ to $4.8 \%$, recurrence of hemorrhage from $9.6 \%$ to $3.6 \%$, and overall mortality in terms of up to 3 years of follow-up from $57.7 \%$ to $44.6 \%$. The diameter of the EVV was initially approximately the same in both groups (P>0.05). In terms of 1 month after $E L$, the diameter decreased in the main group from $3.44 \pm 0.21 \mathrm{~mm}$ to $2.85 \pm 0.12 \mathrm{~mm}(P<0.05)$, in the control group after ES from $3.41 \pm 0.19 \mathrm{~mm}$ to $3.02 \pm 0.17 \mathrm{~mm}$. At the same time, the degree of diameter reduction was also significant $(\mathrm{P}<0.05)$, but when comparing these indicators between the groups, a significant difference was also revealed. The same trend was revealed when comparing data on the number of varicose veins. If in the control group the average indicator initially amounted to $2.78 \pm 0.13$ and a month after ES decreased to $2.34 \pm 0.18(P<0.05)$, in the main group the number of barrels decreased from $2.82 \pm 0.18$ to $2.15 \pm 0.16(P<0.05)$, which also significantly differed from the indicator in the control group. It should be noted that both groups showed a reverse increase in both the number and diameter of veins at 6 months, but this trend was slightly less pronounced in the main group ( $P<0.05$ - at 6 months of follow-up). In the future, by 12 months or more of observation, varicose veins in the diameter and number of trunks were actually completely restored in both groups (table 4).

\section{Table 4}

Dynamics of the EVV diameter and the number of venous trunks after endoscopic hemostasis in the study groups 
The American Journal of Medical Sciences and Pharmaceutical Research (ISSN - 2689-1026)

Published: August 02, 2020 | Pages: 1-10

Doi:https://doi.org/10.37547/TAJMSPR/Volume02Issue08-01

\begin{tabular}{|l|l|l|l|l|l|l|}
\hline \multirow{2}{*}{$\begin{array}{l}\text { Observation } \\
\text { time }\end{array}$} & $\mathrm{N}$ & $\begin{array}{l}\text { Main group } \\
\text { Average } \\
\text { diameter } \\
\text { BPBח (MM) }\end{array}$ & $\begin{array}{l}\text { Number of } \\
\text { barrels }\end{array}$ & $\mathrm{n}$ & $\begin{array}{l}\text { Average } \\
\text { diameter } \\
\text { BPBП } \\
\text { (MM) }\end{array}$ & $\begin{array}{l}\text { Number of } \\
\text { barrels }\end{array}$ \\
\hline Initially & $\mathrm{n}=83$ & $3,44 \pm 0,21$ & $2,82 \pm 0,18$ & $\mathrm{n}=52$ & $3,41 \pm 0,19$ & $2,78 \pm 0,13$ \\
\hline 1 month & $\mathrm{n}=34$ & $\begin{array}{l}2,85 \pm 0,12 \\
* \#\end{array}$ & $\begin{array}{l}2,15 \pm 0,16 \\
* \#\end{array}$ & $\mathrm{n}=22$ & $\begin{array}{l}3,02 \pm 0,17 \\
*\end{array}$ & $\begin{array}{l}2,34 \pm 0,18 \\
*\end{array}$ \\
\hline 3 months & $\mathrm{n}=27$ & $\begin{array}{l}2,81 \pm 0,11 \\
*\end{array}$ & $2,21 \pm 0,16$ & $\mathrm{n}=16$ & $2,96 \pm 0,14$ & $2,25 \pm 0,13$ \\
\hline 6 months & $\mathrm{n}=23$ & $\begin{array}{l}3,04 \pm 0,17 \\
\#\end{array}$ & $\begin{array}{l}2,35 \pm 0,20 \\
* \#\end{array}$ & $\mathrm{n}=14$ & $\begin{array}{l}3,19 \pm 0,16 \\
*\end{array}$ & $\begin{array}{l}2,41 \pm 0,15 \\
*\end{array}$ \\
\hline 1 year & $\mathrm{n}=25$ & $\begin{array}{l}3,25 \pm 0,24 \\
*\end{array}$ & $2,49 \pm 0,15$ & $\mathrm{n}=17$ & $\begin{array}{l}3,35 \pm 0,18 \\
*\end{array}$ & $\begin{array}{l}2,54 \pm 0,18 \\
*\end{array}$ \\
\hline $\begin{array}{l}\text { Up to } \\
\text { years }\end{array}$ & $\mathrm{n}=28$ & $\begin{array}{l}3,40 \pm 0,25 \\
*\end{array}$ & $\begin{array}{l}2,65 \pm 0,22 \\
* \#\end{array}$ & $\mathrm{n}=19$ & $\begin{array}{l}3,52 \pm 0,21 \\
*\end{array}$ & $\begin{array}{l}2,84 \pm 0,19 \\
*\end{array}$ \\
\hline
\end{tabular}

Note: * - confidence $(P<0.05)$ differences from the previous indicator; \# - confidence $(P<0.05)$ of the difference from the indicator in the control group. As for the "compensatory" increase in varicose veins outside the zone of endoscopic hemostasis, in both groups, this indicator gradually increased with observation to approximately the same extent. While $85.3 \%$ of patients in the main group and $86.4 \%$ in the control group had no increase in varicose veins during the follow-up period up to 1 month, this indicator remained unchanged for more than 1 year only in $10.7 \%$ and $15.8 \%$ of patients, respectively (Fig.2). 


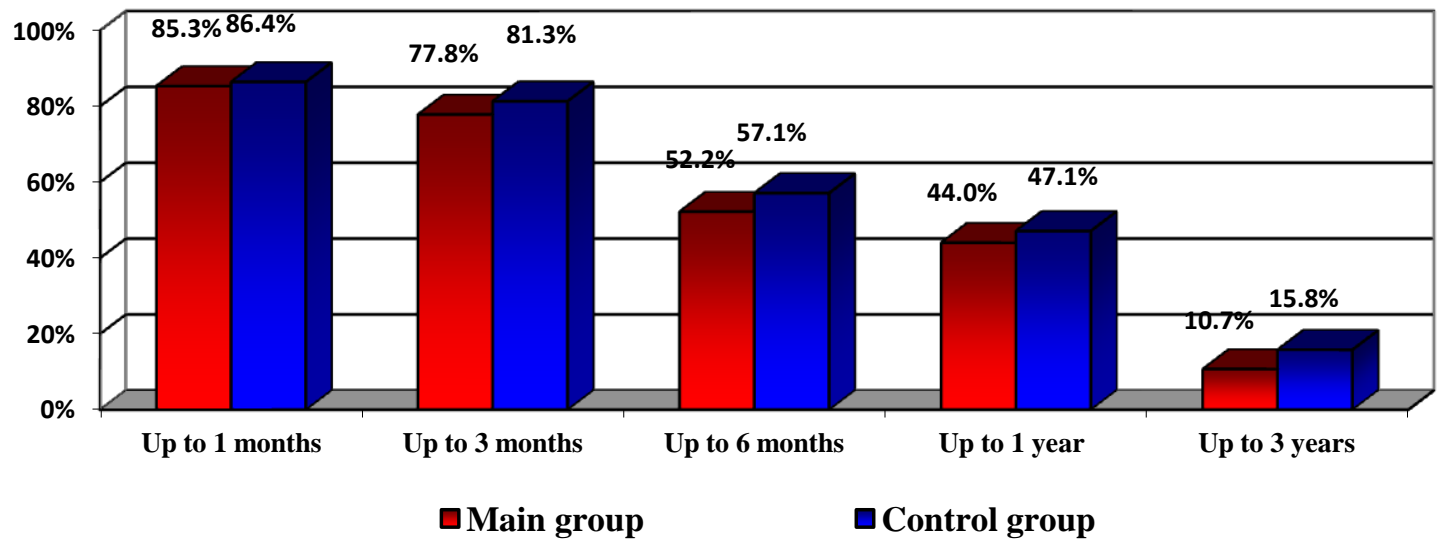

Figure 2. No progression of varicose veins outside the zone of endoscopic hemostasis in the study groups Progression of varicose veins outside the zone EL caused from 1 to 3 additional sessions to be performed EL in 34 patients of the main group and 18 patients in the control group (table 5).

Table 5

Dynamics of EVV regression depending on the number of sessions of endoscopic hemostasis

\begin{tabular}{|l|l|l|l|l|l|l|}
\hline \multirow{2}{*}{$\begin{array}{l}\text { Number } \\
\text { additional sessions }\end{array}$} & \multicolumn{5}{|l|}{ Average diameter of varicose veins } \\
\cline { 3 - 7 } & \multicolumn{2}{|l|}{ Main group } & \multicolumn{3}{l|}{ Control group } \\
\cline { 2 - 7 } & $\mathrm{n}=$ & Before & After & $\mathrm{n}=$ & Before & After \\
\hline 1 session & 34 & $\begin{array}{l}3,10 \pm 0,1 \\
2\end{array}$ & $\begin{array}{l}2,09 \pm 0,15^{*} \\
\#\end{array}$ & 18 & $\begin{array}{l}3,16 \pm 0,1 \\
7\end{array}$ & $2,56 \pm 0,15$ \\
\hline 2 sessions & 21 & $\begin{array}{l}2,94 \pm 0,1 \\
4\end{array}$ & $\begin{array}{l}2,06 \pm 0,10^{*} \\
\#\end{array}$ & 14 & $\begin{array}{l}3,02 \pm 0,1 \\
3\end{array}$ & $2,53 \pm 0,16$ \\
\hline 3 sessions & 11 & $\begin{array}{l}2,75 \pm 0,1 \\
8\end{array}$ & $\begin{array}{l}2,25 \pm 0,12^{*} \\
\#\end{array}$ & 6 & $\begin{array}{l}2,95 \pm 0,1 \\
5\end{array}$ & $2,51 \pm 0,18$ \\
\hline On average & & $\begin{array}{l}2,93 \pm 0,1 \\
1\end{array}$ & $\begin{array}{l}2,13 \pm 0,10^{*} \\
\#\end{array}$ & & $\begin{array}{l}3,04 \pm 0,1 \\
2\end{array}$ & $2,53 \pm 0,14$ \\
\hline
\end{tabular}

Note: * - reliability $(\mathrm{P}<0.05)$ of the difference from the es session indicator; \# - confidence $(\mathrm{P}<0.05)$ of the difference from the corresponding indicator in the control group. The average period between sessions was $2.82 \pm 0.74$ months and ranged from 1 to 10 
months. In the main group, a good endoscopic effect was obtained regardless of the number of El sessions.in all cases, a significant $(P<0.05)$ difference was obtained, both in the regression of the vein diameter and in comparison with the same indicator in the control group.

\section{CONCLUSION}

The study made it possible to draw the following conclusion.

With active bleeding, the frequency of unsatisfactory ES results followed by the use of a standard Blackmore-Sengstaken probe, depending on the source level and intensity of bleeding, ranges from $16.7 \%$ (n/3, Forrest I-B) to $66.7 \%$ (stomach cardia, Forrest $\mathrm{I}-\mathrm{a}$ ), on average $31.1 \%$.

The use of endoscopic ligation increased the rate of effective hemostasis from $68.9 \%$ to $83.1 \%$, while the use of such a technique for active bleeding from the most difficult area for endoscopy - stomach cardia improves the hemostatic effect from $42.9 \%$ to $61.5 \%$.

In patients with $\mathrm{COL}$ with $\mathrm{PH}$ complicated by stopped bleeding, the frequency of early recurrence of bleeding after ES with subsequent use of the Blackmore-Sengstaken probe can reach $18.5 \%$ of cases, in turn, endoscopic ligation of the source of bleeding reduces this indicator to $9.4 \%$, while, depending on the level of the source of primary bleeding, the highest probability of recurrence, reaching $37.5-60.0 \%$, is detected in the area of the stomach cardia, while the probability of recurrence from the $n / 3$ esophagus does not exceed $5 \cdot 4-13.0 \%$.

In patients with $\mathrm{CoL}$ with a history of $\mathrm{PH}$ complicated by bleeding from the VVEaS, performing a single session of EL allows to achieve a regression of the vein diameter by an average of $18.3 \%$ (from $3.44 \pm 0.21 \mathrm{~mm}$ to $2.81 \pm 0.11 \mathrm{P}<0.05)$ and reduce the number of venous trunks by $23.8 \%$ (from $2.82 \pm 0.18$ to $2.15 \pm 0.16 \mathrm{P}<0.05)$. At the same time, after $\mathrm{EL}$, there is a reverse progression of EVV with virtually complete recovery by 1-3 years of follow-up and an increase in the frequency of recurrent bleeding to 38.6-51.9\%, which requires timely treatment of patients in a specialized Department for radical correction of $\mathrm{PH}$ syndrome or repeated palliative ES sessions.

\section{REFERENCES}

1. Nazirov F. G., Akilov H. A., Devyatov A.V. Surgery of portal hypertension complications in patients with cirrhosis of the liver. - M.: GEOTAR Medicine.-2002. $414 \mathrm{p}$.

2. Nazirov F. G., Devyatov A.V., Ibadov R. A., Mirzaev B. B. Perspective directions of minimally invasive surgery of portal hypertension. // Surgery Of Uzbekistan Tashkent 2005. - No. 1. - P. 17-24.

3. Andreev G. N., Apsatarov E. A., Ibadildin A. S. Diagnostics and treatment of portal hypertension complications. Almaty. Kazakhstan. 1994. 320C.

4. Eramishantsev A. K., Kitsenko E. A., the Use of nitroglycerin and B-blockers for the prevention and treatment of bleeding from varicose veins of the esophagus and stomach. Bleeding in diseases of the gastrointestinal tract. Novosibirsk, 1994, p. 7-9.

5. Makienko I. A. Prevention and treatment of bleeding from varicose veins of the esophagus and stomach in cirrhosis of the liver. Abstract of dissertation of the candidate of medical Sciences. Novgorod, 2004.

6. Kadirov R.N., khadjibaev F. A. Quality of life of patients in the immediate period 
Doi:https://doi.org/10.37547/TAJMSPR/Volume02Issue08-01

after relief of gastroesophageal bleeding depending on the applied methods of hemostasis. // Emergency medical care " Russian scientific and practical journal, Vol. 21, no. 2, 2020g.

7. Abraldes JG, Angermayr B, Bosch J. the management of portal hypertension [review]. Clin Liver Dis 2005;9: 685-713.

8. De Franchis R, Dell'era A, Fabris $F$ et al. Medication for portal hypertension. Acta
Gastroenterol. Belg., 2004. OctoberDecember; 67 (4): pp. 334-43; discussion 344-5.

9. Kadirov R.N., khadjibaev F. A., Akhmedov Yu. M. Quality of life of patients in the near term after the appointment of gastroesophageal bleeding depending on the applied methods of hemostasis / / American Journal of Medicine and Medical Sciences 2020, 10(5) 